Working Papers on The Nature of Evidence: How Well Do 'Facts' Travel?

No. $39 / 10$

\title{
Facts and Building Artefacts: What Travels in Material Objects?
}

Simona Valeriani

(c) Simona Valeriani, LSE 


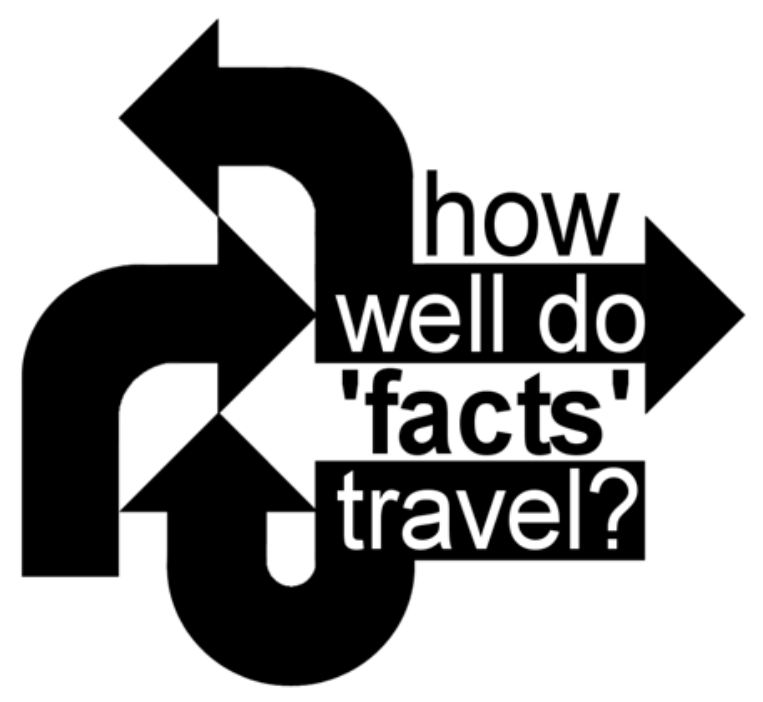

"The Nature of Evidence: How Well Do 'Facts' Travel?" is funded by The Leverhulme Trust and the ESRC at the Department of Economic History, London School of Economics.

For further details about this project and additional copies of this, and other papers in the series, go to:

http://www.Ise.ac.uk/collection/economichistory/

Series Editor:

Dr. Jonathan Adams

Department of Economic History

London School of Economics

Houghton Street

London, WC2A $2 \mathrm{AE}$

Tel: $\quad$ +44 (0) 2079556727

Fax: $\quad$ +44 (0) 2079557730 


\section{Facts and Building Artefacts: What Travels in Material Objects?}

Simona Valeriani*

\section{Introduction: Travelling Through Cultures, Travelling Through Time}

Facts are often expressed as statements or verbal descriptions. But in some cases, facts - particularly facts about technology - are better recorded and transmitted via material objects. ${ }^{1}$ Does the nature of the vehicle that contains and expresses (and sometimes almost constitutes) the facts influence how they travel and are received? This chapter contributes to the question of how material objects carry facts from one culture to another, and through the centuries, by considering some examples from the history of construction, while at the same time keeping in mind the praxes of archaeologists, historians, conservators and museum curators. Therefore, we will be dealing with facts travelling on two different levels: facts travelling in a material object to the observer or user, as well as facts from and about buildings travelling in the realm of architectural history.

Material objects can 'carry' facts through different trajectories across time, of course, but also from one cultural audience to another, which might include a geographical move or might not. Analysing a building or its components - or an archaeological excavation and the

\footnotetext{
* I would like to thank the many people who helped me think about these issues and gave important feedback on earlier versions of this chapter, particularly Mary Morgan and Peter Howlett, the members of the facts group, and its guests, for conceptual suggestions; David Yeomans for our discussions on English and Italian carpentry and Jon Morgan for his editorial help. My thanks go also to the Leverhulme Trust and ESRC, that generously financed the "How well do Facts Travel?" Project (grant number: F/07004/Z), and gave me the opportunity to conduct this piece of research. ${ }^{1}$ In recent years, a growing number of scholars has been concerned with the concept of materiality and 'thingness,' either from a more theoretical perspective (e.g., Brown 2004, Baird 2004, Buchli 2004 and Miller 2005) or from an anthropologicalarchaeological point of view (e.g., Buchli 2002 and Tilley 2006).
} 
artefacts found in it - gives us 'clues' about those historical events and processes that directly involved and physically shaped the objects concerned: their production, the use that was made of them, possible repairs, changes and so on. The primary vehicle by which these (historical) facts travel is the material object itself, although other means must often be taken into consideration as well to get at the whole story. Following facts through these two trajectories of time and space, we ask which 'facts' travel, via which vehicles and what happens to them when they travel. A specific example may help to make these questions more concrete.

\section{Building Structures, Inscriptions and the Shaping of Identity Case 1: St. Cecilia in Trastevere}

If you visited the loft space of the church of St. Cecilia in Trastevere in Rome, you would be surprised to notice that both the walls and the roof structure are highly decorated (Figure 1). You might then logically conclude that the vaulted ceiling that nowadays covers the nave is a later addition. Looking in detail at the roof, you would be able to describe the kind of structure (a so-called simple palladiana), to see that the beams are painted with both geometric and figurative motifs, to notice that most of the beams have marks carved on them near where they connect to other elements of the frame and finally - if you wriggled between the vault and the roof structure and looked really carefully - to discover an inscription underneath beam no. 5 testifying to the construction works on the church as having been carried out in 1472 following instructions given by Cardinal Niccolò Fortiguerra. 
Figure 1: St. Cecilia in Trastevere in Rome.

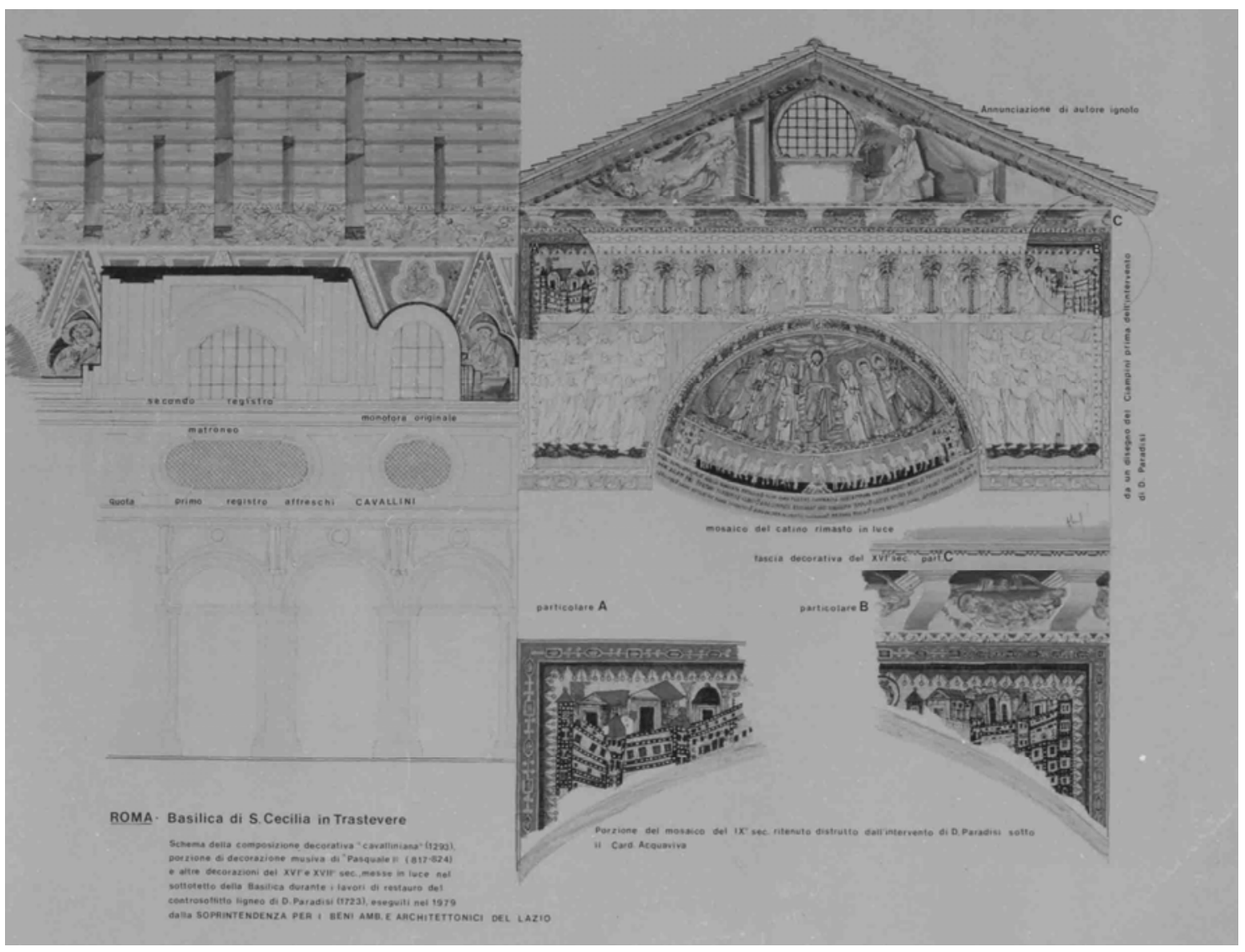

Left: longitudinal section of the basilica showing (from the top down) the roof structure, the painted freeze from the sixteenth century, the medieval wall paintings with apostle figures, the profile of the vaults dating to the eighteenth century and the interior of the church. On the right (top): cross-section of the church showing (from the top down) the roof covering, the Annunciation and the freeze painted in the sixteenth century and the mosaics from the ninth century, of which only the apse dome is nowadays visible from the church. On the right (bottom): details of the decoration. From Valeriani 2006a, courtesy of the photographical archive of the Soprintendenza per i Beni Architettonici e del Paesaggio di Roma.

Clearly, the material object is telling a story - or, at least, it is providing the interested observer with a host of facts and clues so they can tell the artefact's story. Most evidently, these travelling facts are about the structure of St. Cecilia and how it holds up, telling us about the know-how of the builders who erected the building: The kind of structure that was used and how the joints work, for example, are directly observable. Intentionally left traces carry facts relating to its production. 
The carved marks give clues about the assembly method and the organisation of the work on the building site, evidence that the structure was preassembled elsewhere, transported to the building site and then reassembled following these marks - they are a sort of 'incorporated user manual.'

But this will set off an alarm bell in the mind of a historian, who will recognise this 'fact' as being very unusual (Roman Renaissance carpenters did not use marks for such reassembly processes) and start to wonder if the carpenters who worked here might have come from other regions. The facts as to 'why' this uncommon technique was used are not to be found in the object itself, of course: They need to be searched for in the archives. But we will look into the matter of the archives in more detail in the second case study. The observation that nearly all of the elements composing the roof frames have carved marks that seem to fit in the same system indicates that most of the roof structure originated in the same building phase. This is already a clue toward constructing the chronological sequence of our story. And indeed the artefact carries a number of facts about both its production and its life. The specific relationships between individual parts (A covers $B$, which covers $C ; Y$ cuts $Z /$ is cut by $X$, etc.) will be key in enabling us to construct a chronological sequence logically. This, in turn, can then be linked to an absolute chronology through laboratory analysis of the elements, or by comparing the object and its characteristics with others known to us from other contexts. For such comparisons to be more effective and significant, the reference materials need to be organised into typologies, which, taken together, build up what (later in the chapter) we call 'the encyclopaedia', which can then be used, for example, for dating the mosaics and frescos or the paintings on the beams in stylistic terms. Here, since the apparent 'facts' (the marks) about its assembly method don't align with what we know (from the encyclopaedia) about contemporary local building 
techniques, they may be giving us clues about 'other facts. Following up on such clues, like a detective, may direct us to facts about the import of a specialised workforce from another region, in turn increasing our knowledge about workforce migration patterns.

But, if we return to tie beam no. 5, the story begins to reveal even more complex depths. On the face of it, the material object is being used as a substrate carrying propositional knowledge, in the same way as a piece of paper might. Its inscription asserts the 'fact' that the structure was built in 1472 under the patronage of Cardinal Niccolò Fortiguerra. The problem with this inscription arises when the results of the dendrochronological analysis suggest that the tree from which tie beam no. 5 came was not felled until after 1588 - more than a century after the beam's inscription date. ${ }^{2}$ If this is true, the material object is carrying misleading facts. ${ }^{3}$ Of course, this peculiarity calls for a historical explanation: To make the next step in our 'story telling' we now need to use our interpretative skills to a greater degree and turn for help to other kinds of sources, namely written ones. Indeed, while the material object carries a wealth of signs and facts about what happened and when (in this case, for example, about when the tree was felled, which points to the deliberate 'faking' of the inscription), it is often the case that the use of other sources is needed in order to address questions about why these things happened.

The available documents, together with stylistic analysis, confirm that the pictorial decorations on the roof frame can all be dated to 1599 , which fits well with the dendrochronological results for beam no. 5 . Moreover, the coats of arms displayed as part of the decorations of the

\footnotetext{
${ }^{2}$ In this specific case the data are to be taken with caution because the master chronology has not been finalised; here, for the sake of argument, we will take this as an established fact.

${ }^{3}$ Here (and throughout this chapter) the expression 'misleading' is used in the sense of deliberately misleading. Compare with Haycock, this volume, who provides a discussion of facts as misleading, or false, facts in a very different context.
} 
beams (supported by the age of the wood in beam no. 5) confirm the attribution of these building works to the patronage of Cardinal Emilio Sfondrati (1560-1618). He was a major figure in the counter-reformation movement, who put enormous effort into strengthening the image of the Catholic Church by reinforcing its identity as being the authentic heir to the 'church of the origins' dating from the time of the apostles and the first centuries. Cardinal Sfondrati's 'intervention' at St. Cecilia shows how material objects were used in seventeenth-century Rome to carry and communicate to the observer a series of 'facts'. In this case, the material evidence shows that he chose to incorporate the existing roof within a new scheme of interior decoration, whose purpose was to express theological, political and ecclesiastical 'messages' that were particularly close to his heart.

A bit of historical knowledge is needed to support this interpretation. The informed viewer will know that the church of St. Cecilia was first built in early Christian times and has undergone several subsequent renovations. And they will also know that although both flat ceilings and visible roofs had been used in basilicas since antiquity, there was a marked preference for the latter in Rome until the Renaissance and that vaults above aisles and flat ceilings above naves became quite common during the fifteenth century. ${ }^{4}$ Despite that, the visible roof of St. Cecilia was preserved and the very materiality of its trusses was seen as evidence of the church's long and venerable history. ${ }^{5}$ The trusses were made more appealing and 'relevant' for the contemporary observer by 'modernisation' - to this end, the old roof structure (at that point in time

\footnotetext{
${ }^{4}$ However, this trend was not universal, and even in the seventeenth and eighteenth centuries some restorations preserved the original layout.

${ }^{5}$ Cardinal Sfondrati did consider inserting a new ceiling in line with the architectural fashion of the moment, but then decided otherwise. Part of the reason was structural in nature, as the architect expressed concern about the capability of the walls and columns to carry the additional load (Valeriani 2006a, p. 49 and Valeriani 2006b). Nevertheless, it is remarkable how the patron used the existing building elements to express his political message.
} 
visible from the nave) was decorated with paintings whose theme (the Arma Christi) reflects the counter-reformist desire to exalt martyrdom and sanctity. ${ }^{6}$ This made the roof an integral part of the spatial, decorative and political concept of the church, whose different elements, in their materiality, were taken to embody facts about the past, but which were also relevant for the present and the future. The mosaics above the arch and the opus sectile floor of the St. Cecilia chapel and the remains of the saint were seen as material evidence of the building's paleochristian origin; the frescoes on the sidewalls of the nave as a testimony of the medieval period; the roof structure and the Fortiguerra coats of arms (and the inscription on tie beam no. 5) as further links in the uninterrupted chain of the church's history from its origins to the contemporary period (Figure 2).

${ }^{6}$ See Valeriani 2006a, pp. 49-52. 
Figure 2. St. Cecilia in Trastevere in Rome

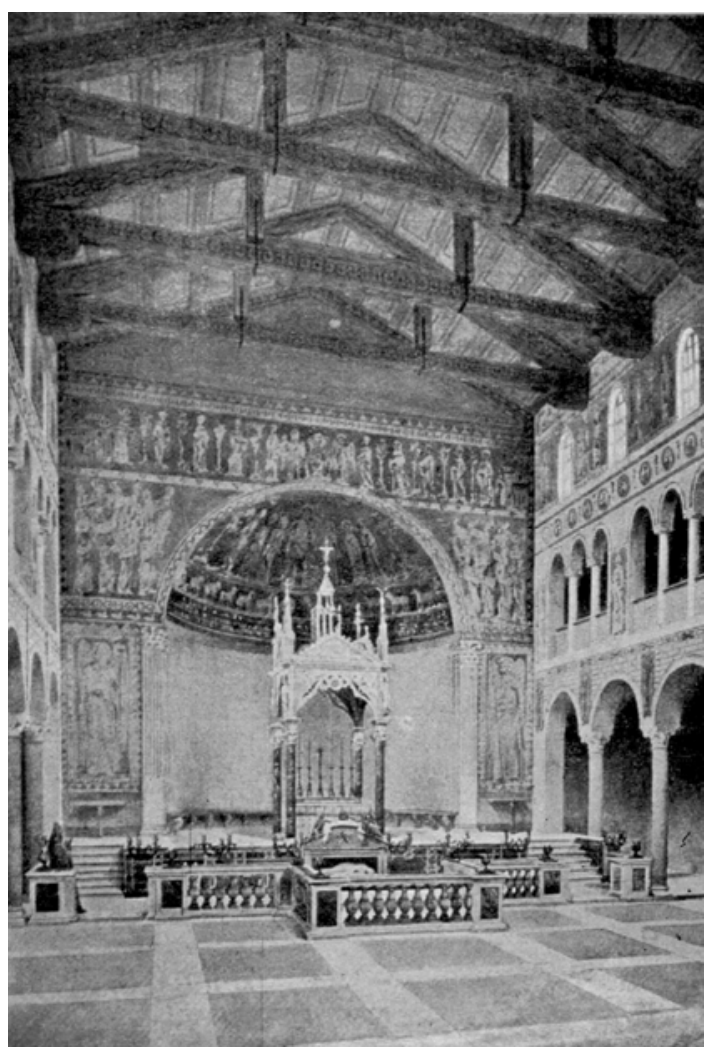

Graphic reconstruction of interior before the insertion of the vaults in the eighteenth century. Decorations from different époques were visible simultaneously. Giovenale, Giovanni Battista. "Recherches architectoniques sur la Basilique de S. Cecilia," Cosmos Catholicus. Le monde Catholique illustré, 4 (1902), p. 670.

The very materiality of all these elements underlined their role as a tangible testimony and a powerful symbol of the centuries-old ecclesiastical tradition, and was therefore worth preserving (or even faking if not in a good enough state of conservation). I suggest we can argue that the beam's inscription was a late-sixteenth-century fake (which, in our terms, has endowed the beam with misleading facts) intended to replace a broken link in the chain of meaning stretching back from that time of counter-reformation to the church's historic origins. In the mind of a seventeenth-century patron, the material object was an excellent carrier of facts. In a similar fashion, St. Cecilia is a fascinating building for the historian today, carrying a richness of facts about the past: 
not only those introduced by Sfondrati's renovation and conservation efforts, but also many other clues of a technical and historical nature, carved (more or less intentionally) into the artefacts by their many makers and users, which can richly repay further detective work.

\section{Material Objects as Carriers of Travelling 'Facts'}

\subsection{Artefacts and the Complexity of Travelling Facts}

It is evident that the kind of facts we can 'read out of' an object depends also on the question the observer has in mind - the more complex the material object, the more layered the set of facts that may be travelling with it. ${ }^{7}$ If we consider a building, for example, it will often 'carry' a variety of different kinds of facts in different forms (more or less visible, and more or less dependent on our analytical and interpretative skills for their understanding). Buildings (or even town settings) are often conceived as instruments for communicating something about the patron or the way the society is organised and ruled. But they also tell all sorts of other stories about the scientific and technical knowledge needed to realise them, the techniques used to produce them and how the production process was organised, the building materials offered by the local natural environment, etc.

This weaving of different kinds of facts transmitted in the material object (within or on its surface) is precisely the core of the case studies illustrated in this chapter. ${ }^{8}$ Technical elements (such as roof structures) are taken as the repository of facts about craftsmanship and technical

\footnotetext{
${ }^{7}$ Another example of a complex object carrying a layered set of facts can be found in the composite images utilised in scientific journals, which is discussed by Merz in Howlett and Morgan (forthcoming).

${ }^{8}$ Howlett and Velkar in Howlett and Morgan (forthcoming) also discuss how material objects carry technological and technical facts, while (in contrast) Leonelli (also in Howlett and Morgan (forthcoming) shows how digital traces (materials, as opposed to words or texts) carry the facts.
} 
knowledge, but also as vehicles for the transmission of symbolic facts. The cases briefly presented here were chosen to reflect the complexity of the travelling mechanism. They are not, of course, illustrative of all the possible kinds of facts that travel and their ways of travelling, but are used to ground considerations about the relationship between material objects and travelling facts more firmly in their materiality. The focus is on which kind of facts travel through the material objects and what happens to them in doing so. Some attention is given also to which kind of facts do not travel in such artefacts, as well as to which elements of the historical narrative emerging from each case study may derive from other sources. The examples concern actual buildings and the attempt to reconstruct their history over the centuries. Embracing the building archaeology approach, the material evidence is understood as the first source for historical enquiry. In both cases presented in this chapter, the analysis starts with the roof structures and the loft spaces, which (since they constitute areas of buildings that are less frequently modernised) may be where original remains, and also subsequent developments, are easier to recognise a posteriori.

The first example has already shown material objects as carrying a whole set of different layers of facts. Let us now look in more detail into different ways in which artefacts more generally carry facts.

\subsection{Different Forms in Which Artefacts Carry Facts}

We can - at it's simplest - imagine a material object as being used as a substrate to carry propositional knowledge, in the same way as a piece of paper. This happens, for example, on gravestones or plaques, where the inscription and decorative elements are meant to tell the observer some particular facts (as the inscription on beam no. 5 in St. Cecilia purported to do). The material object may not always have been intended to carry such information - sometimes this function was 
attributed to it a posteriori, as in the case, for example, of graffiti (as we will see in the next case study). However, as the materiality of the object concerned plays only an insignificant role, this 'basic' case does not align with the focus of this chapter.

A different manner of fact-carrying concerns signs intentionally left on the object by its makers but not intended for an 'end user'. They were often meant to communicate facts relevant for the production process. When observed by the historian (or other practitioner versed in such objects), these signs act as 'clues' that can be used to retrieve a series of facts 'stored' in the object. The carpentry marks observable on woodframed houses (and wooden structures in general) were symbols or numbers carved in each beam to act as a guide for the carpenter on how to assemble the structure (as at St. Cecilia) - without them it would have been virtually impossible to make sense of the hundreds of timber pieces scattered on a building site. Each single beam carried vital information for the success of the building venture, and - from the historian's point of view - such elements are a precious source of information about both the building process and the technical culture that produced them. Similar considerations can be made when analysing the stonecutter's marks, which are thought to indicate either which artisan made a block or who sourced it, and which therefore 'carry' facts about the division of labour and the accounting mechanisms on a building site, and can also give indirect clues about building sequences. ${ }^{9}$ In both cases, the marks allow the retrieval of quite a complex array of facts, far beyond their original scope.

\footnotetext{
${ }^{9}$ On the general topic of the use and significance of stone masons' marks, see Friedrich1932 and Maier 1975, while for a very nice example of how these traces can be carriers of other facts and help the historian, see Rogacki-Thiemann 2007, pp. 4755.
} 
This brings us to the importance of what we can call the 'encyclopaedia' and the 'typified data'. ${ }^{10}$ The encyclopaedia is an array of examples, materials, etc., built up from observations from many sources that can be compared with what you find to make sense of it in a broader context. Typified data are more specific, in effect storing series of data about similar kinds of elements that can then be subdivided into smaller categories, and help analyse or date a specific element in detail. In some areas, this information can be so specific that it is possible, for example, to date a building (approximately) on the basis of the kind of carpentry marks visible on its beams. ${ }^{11}$

To sum up: The characteristics of material objects shaped in a particular way for a specific purpose are also meaningful to us in the pursuit of other, more general questions. There may be many unintentionally left signs that are traces of an array of processes, actions and facts about the production and the life of the object, the facts' technical nature and, indirectly, social nature.

Some clues are easily seen without the help of any sophisticated devices - but instrumentation and technical know-how may be required to make others visible. The texture of a wood or stone artefact, for example, can tell us much about the tools used for its production - and looking at a tool and the way it has aged can tell the schooled eye what it was used for. But if we, for example, want to retrieve from an ancient vessel facts about what materials it used to contain - which may in turn give us clues as to our ancestors' diets - we will often need to employ more sophisticated techniques. Even facts that are actually visible to the naked eye can remain unrecognised for a period, either because familiarity with the object has decreased over the course of time - and with it the ability

\footnotetext{
${ }^{10}$ Pucci 1994, see later in this paper.

${ }^{11}$ Valeriani 2006a and Valeriani 1999 (with references). Obviously, the problem of reuse and the coexistence of relicts from different building phases need be taken into consideration.
} 
to 'read' such facts - or because the object has come into a geographical environment where it is unknown. The 'failure' of some technical facts to travel well is exposed in cases such as those where attempts to replicate an artefact fall short because the new environment fails to appreciate which of its characteristics are the essential ones. Where a new recipient lacks some key item of knowledge that would allow them to make a 'correct' interpretation of the object, the fact's 'journey' can be seen to have been interrupted.

Nevertheless the object still 'contains' the facts - and another user may be able to discover them. It is just a matter of learning how to 'read' the artefact, ${ }^{12}$ or of deciding which questions need to be asked, which layer of facts brought to the surface. This complex relationship between the object, the marks and the facts they can 'reveal' will be addressed later in the chapter - but, clearly, making sense of the marks and linking them to the facts - which we could say are 'embedded' in the material object - requires a certain degree of expertise. ${ }^{13}$

Linking the physical characteristics of objects to facts about their history or their production, etc., can, in some cases, be quite a complex process. Sometimes the material qualities are enough in themselves but sometimes they only provide us with clues, and extensive 'detective' work needs to be carried out in order to get to the facts. In some cases, the object may carry 'qualities' but without revealing much about the techniques used to produce them. Thus, in preparation for the fivehundred-year anniversary of Columbus's discovery of America, extensive

\footnotetext{
${ }^{12}$ Tarule 2004 presents an interesting investigation of which facts can be read out of an artefact.

${ }^{13}$ The literature is rich in contributions that discuss whether artefacts are social constructed entities highly dependent upon our perception or, in contrast, are to be seen as the most 'objective' and sturdy of all the entities we can study. Taking a pragmatic attitude, many authors are trying to find a balance between the two ideas (see, for example, discussions in Baird 2004, Brown 2004 and Miller 2005; see also the overview offered by Daston 2004 in the introduction (pp. 7-24). This also represents this chapter's take on the matter.
} 
work was undertaken in Genoa's historic harbour, where great celebrations were planned. As historians and archaeologists had warned, excavations for new tunnels brought the medieval quays to light. Apart from questions of how appropriate it was to dismantle these historical structures, a very practical problem also arose: The quay walls, and specifically the mortar in them, were incredibly hard and the work proved much more challenging than expected (Mannoni 1988). Even the best contemporary materials and production processes could not match the extraordinary quality of the mortar, and this discovery kicked off a line of enquiry to try to determine how this had been achieved. ${ }^{14}$ The physical and chemical composition of the mortar was relatively easy to establish, but was not necessarily enough to explain the superior quality of the end product - younger mortars made with similar ingredients failed to perform as well. Further analysis carried out by the Department of Material Sciences at the Engineering faculty in Genoa revealed that the mortar's hardness was linked to particular microstructures, which had evidently been formed in the material through specific processes about which no knowledge seemed to be available. A group of experts have since been working on the topic, interrogating historical sources and experimenting, but while some forward steps have been made in the last twenty years, we are still struggling to match the quality of the medieval mortar exactly. The information stored in the object has only partially helped us solve the mystery - the rest of what we now know has been achieved through study of the production sites and processes (including archaeological investigation, analysis of historical documents and oral history: Vecchiattini 1998, Mannoni et al. 2004) and, starting from those clues, through experiments trying to reproduce the mortar using different

\footnotetext{
${ }^{14}$ Mortars with similar qualities had occasionally been observed previously in different parts of the historical harbour, as well as (for example) in the foundations of Palazzo Ducale, but no systematic enquiry into their composition and historic production had been launched.
} 
settings (Pesce and Ricci in print (2009)). In this case, the artefact didn't carry all the facts about the methods used for its production - but it did demonstrate that it was possible to make such high-quality mortars. Similar stories have been told for many other - more famous - materials, such as porcelain. ${ }^{15}$

\subsection{Little Clues for a Big Question: Which Facts are to Be Found in}

\section{Material Objects?}

So far we have discussed the ways in which facts can travel in (or through) a material object via its material characteristics and (more or less) intentional marks. But what kind of facts travel in these artefacts and which kind of questions can they help us to address?

Facts 'carried' in material objects are of very different kinds and concern the materials and technologies used to make the object as well as how it was used and so on. And these 'material' facts, in turn, will carry facts about the practitioner and the society that produced them: their knowledge, their skills, their taste and maybe even their aspirations, so that this 'fact-carrying' can be seen, in a sense, as closing the gap between the object and its society We could even argue that the artefact is a fact or a collection of facts about material qualities, production techniques, design principles and strategies, trends, customs and social circumstances.

This becomes evident if we take, for example, an object where materials of inferior quality are being used to imitate a product of higher status, as often happens with pottery, porcelain or precious metals. The object can clearly be seen as carrying misleading facts, and it is more

\footnotetext{
${ }^{15}$ It is interesting to note that the hydraulic component of these mortars was known under the name of 'porcellana,' the same word used for 'porcelain.' And indeed this material (kaolin) was an important ingredient in the production of porcelain. It was probably imported by Genoese merchants alongside Turkish alum for which Genoa had long had a monopoly.
} 
likely to do so successfully if it travels from one environment or geography to another. But even if the 'facts' it carries about its material qualities are misleading from the perspective of a social historian, it nevertheless carries 'valid' facts about consumption patterns, taste, fashion, etc. Taking on a false identity often goes beyond the formal similarities expressed in an object's materiality, and is also transmitted through its 'naming' (thus, there is a certain kind of ceramic called 'porcelletta', a name that - falsely, but deliberately - suggests similarities with porcelain). The names attached to material objects can also carry other kinds of misleading facts - history is rich with material objects known under names that relate them strongly with places or personalities to which they are, in reality, only loosely or 'secondarily' connected. ${ }^{16}$ The so-called Genoese pottery and the 'Serlian window' provide good examples. The first was actually produced in southern Spain by Islamic potters, but was named Genoese because it was exported to England via Southampton by Genoese merchants. ${ }^{17}$ The latter is a particularly shaped window (of three parts, with a large, arched central section flanked by two narrower, shorter, square-topped sections) that, in fact, is not at all the invention of Sebastiano Serlio (c. 1475-1555), the famous Italian Renaissance architect, but somehow became attached to his name, and is still regularly identified with his work by the general public - indeed, it has become almost a symbolic element of Renaissance architecture.

Another type of fact that can be seen as adhering to an object without really being part of its materiality is the symbolic fact. It can sometimes be 'readable' from the artefact itself, but in other cases is just attached to it because of its history, or has become known to us through

\footnotetext{
${ }^{16}$ Adams in Howlett and Morgan (forthcoming), provides a discussion of when facts are misleadingly displayed as fiction and vice versa.

${ }^{17}$ Marta Ajmar, presentation at the workshop Facts and Artefacts, LSE, December 2007, paper forthcoming.
} 
oral or written tradition. ${ }^{18} \mathrm{~A}$ decorated sword can be seen as an example where symbolic facts are stored visibly in a material object: The elaborate features of the blade and handle are a clear sign that the object was not exclusively, or even primarily, intended as a fighting or cutting instrument. If we analyse which kind of metal was used and look in detail at the traces of the production process, we will probably be able to tell if it is to be understood primarily as a functional object or as a status symbol ( for example assessing how effective it would have been as a cutting tool versus its decorative elements). ${ }^{19}$ If the sword was found, for example, in a burial site, this set of material traces will tell us quite a lot about the status of the owner. The object carries symbolic facts in different ways: At one level, it works quite plainly as a symbol of the status of the owner, through the unmistakable richness and elegance of the manufacture alone. And beyond that, it carries other, more specifically symbolic facts expressed, for example, through shape and decoration - that are more complex to decode. In studying this artefact, an anthropologist will be more interested in the social implications of the possession of a decorated sword (looking chiefly at the symbolic facts carried by the object), while the historian of technology (seeing mainly the object's technical 'facts') will use it to understand the development of production techniques or warfare.

Symbolic facts can also be loosely attached to an object and not relate to its materiality at all. Examples of this could be the pictures and objects that Freud used in his famous practice, which are particularly interesting to us because they symbolise his preferences and his 'worldview'. But - to be relevant to us - someone must tell us their story

\footnotetext{
${ }^{18}$ Interesting contributions to this topic were made during the Facts and Artefacts' workshop organised by the author at LSE in December 2007; for details see http://www.Ise.ac.uk/collections/economicHistory/Research/facts/WorkshopSimona.htm.

${ }^{19}$ Here, my thanks go to Susan La Niece (British Museum) who shared her knowledge on the matter with me.
} 
and explain the context they come from. ${ }^{20}$ Our museums are full of objects whose material qualities have no particular value but which we preserve and admire because of their symbolic value (and a similar process of attaching 'symbolic facts' to an artefact relatively independently from its materiality happens, of course, with sacred objects).

These are extreme examples, where a whole range of additional information - other than the artefact itself - is needed if the facts are to travel. An object itself can often tell only part of its own story - evidence about 'how and why' a particular object happened to be built/produced/used at a particular time and place often has to be searched for in other places, 'outside' the artefact. In this case, the artefact itself will not be the only vehicle via which facts travel - its materiality also signals the existence of interesting facts and encourages the informed observers to go and seek explanations for them.

Therefore, material objects may serve the function of being a sort of 'springboard for enquiry', perhaps by carrying facts which signal anomalies that call for an historical explanation. An example could be an artefact of unusual shape found in a burial, where its atypical shape, material or production technique sets off an alarm in the mind of the scholar, who then looks for other clues and, after further consideration and cross-referencing (using, for instance, the encyclopaedia and the typified data), interprets this (perhaps) as evidence of the dead person being a migrant from a distant country. In this sort of case the object itself carries the fact of its 'difference': It tells the observer (both then and now) that (for example) this building design, this structure, this concept of how its plan is organised, how people circulate, which functions are performed where, etc., exists and does work - even though it is alien to the local

${ }^{20}$ This point is also made in a different context by Merz (in Howlett and Morgan (forthcoming) in discussing the use of nanotechnology to create the IBM logo. 
tradition (the case study presented next will allow us to consider this in more detail).

In order to get from the 'little clues' to the 'big questions,' the archaeologist uses a two-part process: He starts with an 'objective' analysis of the artefact (often exploiting data-gathering and analytic methods from the natural sciences) and of its spatial relationship with the surrounding layers. ${ }^{21}$ After this he makes a more interpretative effort to answer questions of the 'why' and 'how' kind. As Andrea Carandini notes about the archaeological method and stratigraphy:

The stratigraphic units are the result of actions, but many analytically identified actions still cannot give the sense of an activity; in the same way that a single observation carried out on the crime scene doesn't automatically explain to Sherlock Holmes the reasons behind the criminal's actions. In archaeology, the sense of an activity is decided by the archaeologist's interpretation of a group of minimal actions... In the process of getting from the single actions to the activities, and from those to the activity groups, and finally to the events/periods, the synthesis is increased, and with it the degree of subjectivity of the interpretation. ${ }^{22}$

\section{History, Archaeology and the Evidence-Facts Question - Archaeologists versus Historians; Bricks versus Paper}

We have seen the particular ways in which material objects carry facts and how the information stored in the objects sometimes needs to be complemented via data deriving from other sources to be able to fully make sense of the object. If the materiality of the sources of our facts does matter - if they carry different information/facts than do texts (or carry them differently from how texts would carry them) - then we should

\footnotetext{
${ }^{21}$ The notion of 'mediating facts' is discussed by Alison Wylie in Howlett and Morgan (forthcoming).

${ }^{22}$ Carandini [1991] 2000, p. 67, translated by author.
} 
expect to find differences in the work by scholars dealing with different sources. Given my background, I focus here on the different disciplines dealing with the study of the past and look at 'historianship' (in the narrower, traditional sense of the word) and archaeology, the kind of historical study most concerned with material objects.

In this context, the positions taken by some archaeologists in the methodological debate that heated the community of historians in the late 1970s and early 1980s (and since) seem particularly revealing. The discussion was prompted by Carlo Ginzburg's brilliant and influential description of how the historian uses evidence in his essay 'Spie. Radici di un paradigma indiziario,23 (and followed up in other well-known contributions to the topic, chiefly in his book Clues, Myth, and the Historical Method ${ }^{24}$. Ginzburg's proposition was that the historian works with a method based on clues, which is fundamentally different from the Galilean paradigm that forms the basis of natural science reasoning. The historian doesn't aim at reconstructing general rules, but particular histories, employing a 'clue-following' methodology resembling that of our hunting ancestors. This 'paradigma indiziario' (conjectural paradigm), he suggests, became more widespread in the nineteenth century, when many disciplines that use this methodology were codified. These include (arguably most famously) Freud's psychoanalysis, with its interpretation of dreams and their details, as well as Morelli's method of attribution of paintings based on apparently insignificant features (such as fingernails, toes, lobes, etc). Medical semeiotics and criminology (with the development of fingerprint recognition) can be added to the list, as well as (albeit in a fictional setting) the 'methods' of Sherlock Holmes in the new

\footnotetext{
${ }^{23}$ Ginzburg 1978; see also Ginzburg 1983. Much of the discussion concentrated on the question of the 'two cultures,' which I will not take up here in detail.

${ }^{24}$ Ginzburg 1989.
} 
detective novel genre developed in the same years by Arthur Conan Doyle. ${ }^{25}$

It seems particularly relevant for our question of 'What Travels in Material Objects?' to consider how Ginzburg's ideas were taken up by archaeologists. An interesting input was given by Giuseppe Pucci, in the themed issue titled 'La Prova' (The Proof) published by the journal Quaderni storici in 1996. Following a long tradition, Pucci asserts that the terms 'evidence' and 'proof' assume a specific meaning in history and archaeology because the historian and the archaeologist normally don't demonstrate (as might the mathematician or physicist) - rather they persuade by adducing proofs, aimed at convincing their audience through rhetoric:

The archaeologist, more often than he assumes, does not demonstrate; rather, he argues. Demonstration and argumentation both aim to have a conclusion accepted by means of adducing proofs, but the meaning of proof changes with the change of the field of use ... In reality, we can say that archaeological discourse belongs rightfully to the field of rhetoric. ${ }^{26}$

But, Pucci argues, this doesn't affect the rationality and validity of the archaeologist's findings - it simply means they employ a different form of knowledge to the conventional 'scientific' one.

Another interesting reflection on this topic was offered by Andrea Carandini, who asserted the scientific character of the historian's work, contending that continuity can be observed between the Galilean and conjectural paradigms. The soundness of the archaeologist's findings (as of the detective's) is assured by the use of pieces of knowledge derived

\footnotetext{
${ }^{25}$ See also Eco 1983, which deals with the topic of logic, reasoning and Sherlock Holmes' method and the logic of abduction in different disciplines (although not including archaeology). Clue-orientated puzzle-solving is also discussed in the context of medical cases by Ankeny (this volume).

${ }^{26}$ Pucci1994, p. 60, translated by author. See also Ginzburg 1999.
} 
both from the experimental sciences and from different kinds of typological knowledge.$^{27}$ Like Holmes, the archaeologist uses a kind of abduction that aligns with known rules and codices. Pucci makes a similar observation in pointing to the use of typified data and of the 'encyclopaedia' as a fundamental element of archaeological argumentation:

But if it is true that many clues together don't formally constitute a proof, the idea that many convergent clues strengthen the line of reasoning can be maintained, particularly when they agree with the encyclopaedia. We could say that if the symptom/clue is the brick with which the archaeologist builds his building; and if the conjecture represents the project, the mortar is given by the encyclopaedia. When we say encyclopaedia, it is not simply about taking in account quod plerumque accidit. The comparisons, essential in the archaeological argumentation, are more persuasive - we could say that they have a greater proofing strength - when they descend from typified data and, in general, when they are quantitatively significant. ${ }^{28}$

The availability of the encyclopaedia, the collection of examples or even specimens of certain kinds of objects, or buildings or architectural features, is essential if the archaeologist is to be able to interpret clues and construct a narrative. As for the natural scientist, the comparison with only one other instance of the same phenomenon is only relatively significant. The description and cataloguing criteria for the objects also need to be coherent for the comparison to be significant. Therefore, the availability of banks of typified data is an important condition for the development of the interpretation of archaeological materials (such as the carpentry marks noted earlier in this chapter).

It will be argued here that the lack of agreement between Ginzburg and his colleagues depends to a great extent on the different kinds of

\footnotetext{
${ }^{27}$ Carandini [1991] 2000, p. 256.

${ }^{28}$ Pucci 1994, p. 69, translated by author.
} 
sources they use for their enquiry as carrier of facts: material objects and texts. The discussion in the original publications deals with history and the historical method, rather than concentrating specifically on the kinds of sources used. But it should be stressed that archaeologists' 'objections' obviously reflect and elaborate upon their own practice. Therefore, we can argue that the dispute should be seen not as the clash of two views about the historical method, but as echoing the differences between historical disciplines mainly concerned with different sources. In other words, historians and archaeologists use different methods to make their 'facts of the past' travel ${ }^{29}$ because these facts come in different forms. The nature of the vehicle 'containing' the facts influences the travelling process in a complex manner, as we have seen. But, it must be underlined, the difference in the relationship between the historian or the archaeologist and the evidence they use seems to be one of degree rather than one of kind (in fact, the historian also needs to consider the text as a material object in some cases - for example, to prove if a manuscript is authentic, or to judge the significance of the way in which the text is arranged on the page, etc.).

If we look more closely at the archaeologists' responses, we notice two recurring elements: one is the reference to the use of methods derived from the experimental sciences (C14 [carbon-14], dendrochronology, chemical/physical analysis, etc.) and the other has to do with the availability of large numbers of samples and of typified data. The possibility of conducting various types of analyses from the natural sciences is clearly connected to the material nature of the sources the archaeologist is dealing with. It also reflects the potential of the material object to store, carry and express a layered plurality of facts in a way that is not given to a text. ${ }^{29}$ The expression 'facts of the past' is introduced in Howlett and Morgan (forthcoming),
by Alison Wylie. 
In terms of the use of typified data, it can be said that although the process of comparing with what is understood as 'typical' and the use of series of data are not alien to 'traditional' historians, this method is generally more distinctively characteristic of the archaeologist: Again, it can be argued that this difference is a consequence of their more extensive use of material objects as evidence. It is in this light that we should interpret Pucci's claim that the archaeologist is more similar to the medical doctor and the detective than the traditional historian is:

The traditional kind of historian uses, in fact, methods from the humanist tradition more than those derived from the medical semeiotic, which is fundamentally alien to his culture. The archaeologist working in the field is, on the contrary, forced to use both; he therefore is among the first to have the right to a seat at the same anatomical table as Morelli, Freud and Conan Doyle. ${ }^{30}$

\section{Case 2: St. Paul's Cathedral - The Origin of Christopher Wren's Technical Facts}

As we have seen, the relationship between the facts stored in the object and the encyclopaedia is central to the development of archaeological reasoning. ${ }^{31}$ This next example examines which facts are directly readable in the object and what kind of further interpretative steps need to be taken to tell the artefact's story in its entirety, including understanding why a phenomenon we can still observe took place: why the building was built in terms of its techniques, materials, styles, shape, functional concept, etc.

\footnotetext{
${ }^{30}$ Carandini [1991]2000, p. 256, translated by author.

${ }^{31}$ Here the term 'archaeological' is used in a broad sense to indicate also, for example, building archaeology. The accent is not on excavation but on the kind of history that is chiefly made through the study of material remains.
} 


\subsection{Plaster, Timber and Iron: Facts and Artefacts in St Paul's Lofts}

Climbing up to the whispering gallery in St Paul's Cathedral (16771708) you will notice a small, dark door at the top of the impressive spiral staircase. If you are lucky enough to get hold of a special permit (and the right key), you will be able to open it and enter a fascinating space spanning above the nave. You will be walking on a floor interrupted by the spherical extradoses of the nave's vaults, with the roof structure just above your head. You will notice it is composed of king post trusses (Figure 3) presenting slightly different shapes depending on the portion of the building they are used in - for example, featuring risen tie beams over particularly high vaults, such as the one at the entrance side of the nave.

If you have a closer look at the shape of the elements composing the trusses (particularly the rafters and king posts), you will see that they are often carved out of bigger logs in a way that must have involved wasting wood. The 'head' of the king post is indeed wider than the body, meaning that the sides have had to be subtracted, leaving timber pieces too small to be used for any structural parts. A similar detail also can be observed on the rafters: At their bottom end they are characterized by a 'step' of just a couple of centimetres that leaves the foot thicker than the rest of the beam. This may all appear particularly surprising when we remember that there was a dramatic shortage of timber in England at the time, particularly in London due to intensive building activities after the Great Fire (1666) and to the contemporary demand for new fighting ships after the Anglo-Dutch wars of 1665-67 and 1672-74. But now we are already using our historical knowledge to 'let the objects speak' - we will return to this topic later and use an array of sources to interpret these clues. Here, the artefacts are acting, as mentioned previously, as a sort of 'springboard for enquiry,' giving signs of anomalies that call for historical explanations. 
Figure 3. St Paul's Cathedral, roof truss over the nave.

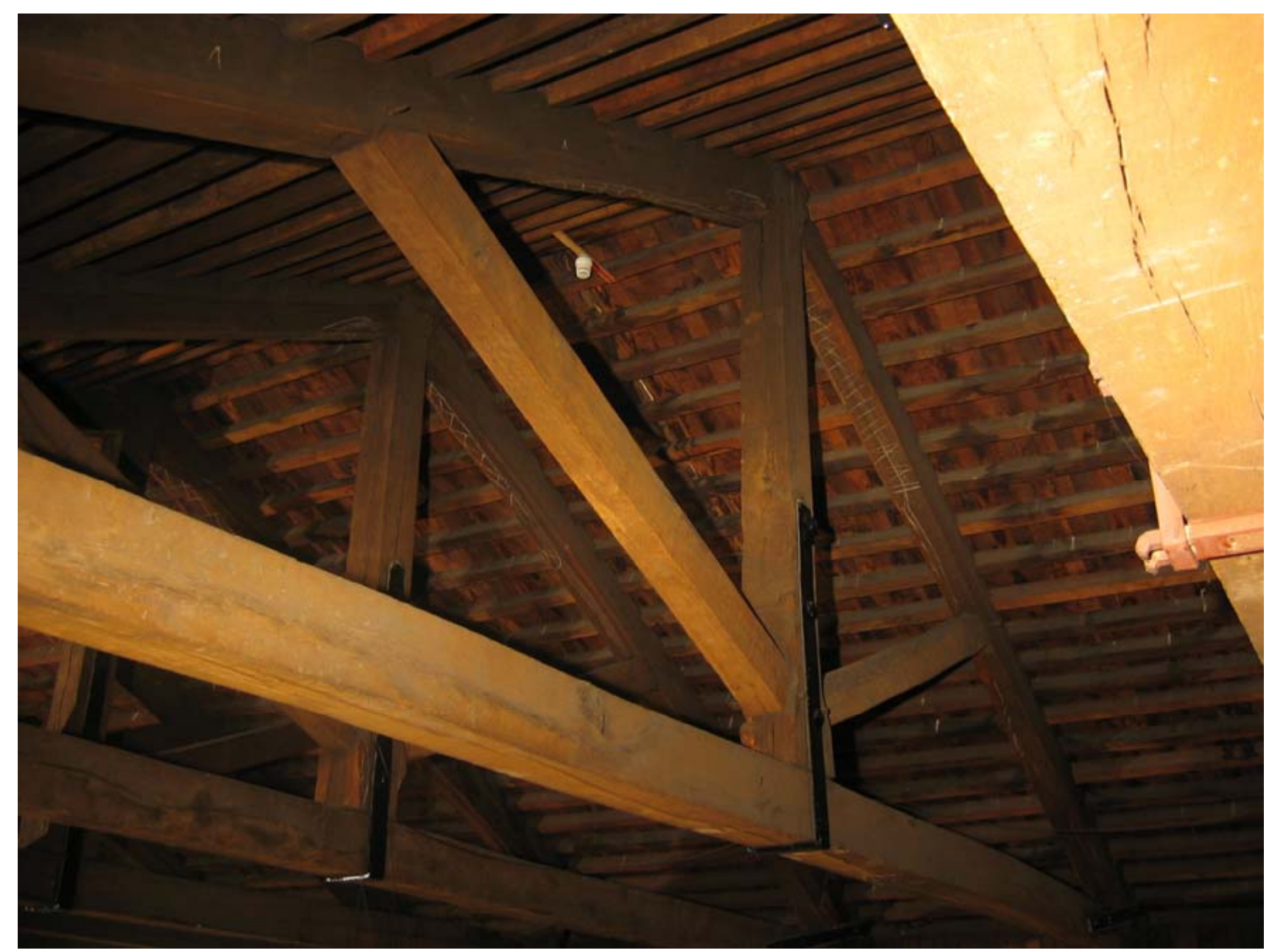

Photo by the author

Other noteworthy details in the roof are the metal elements of different shapes used for different purposes throughout the structure. Metal straps reinforce the connections between posts and tie beams as well as between rafters and tie beams, and other metal bars are used to stabilize the wall-roof structural system above the 'transept.' Looking closely at these elements we will notice that they have features that make it unlikely that they were produced and fitted in the early eighteenth century, suggesting that structural troubles arose after the original construction. ${ }^{32}$

Changes to the structure are suggested also by other clues. The beams composing the trusses are generally marked where they meet with

${ }^{32}$ Confirmed by the written records (Burns 2004, p. 98-101). 
other elements (e.g., at junctions between rafters and tie beams or posts and tie beams and so on). As mentioned before, this is to ensure that the pieces prefabricated off-site are reassembled correctly on-site. In the case of St. Paul's Cathedral, the marks not only indicate which pieces belong together to form which specific truss, but, at least originally, also gave instructions as to the order in which the trusses needed to be erected (e.g., number one is next to the dome, and the numbers progress towards the entrance side). Charting the marks enables us to understand clearly how the assembly process was organised. But it also makes apparent any irregularities in the system that might act as clues toward the fact that the structure was partially mended and reassembled, probably following some kind of damage, in the process of which some original elements were misplaced (the numbers on the trusses are not in the right order). Checking against the historical record, we can see that, in fact, the cathedral was hit by a (luckily) unexploded bomb during World War II, which came through the roof above the quire and shattered the High Altar.

If we then turn our attention to the walls and look carefully in a sidelight, we can make out a graffito carved in the plaster: ' $G$. Reeve May Y3 1705' (Figure 4). Again we have here an example of a material object (in this case, a plastered wall) used as a carrier of facts in the same way as a page, and here it gives us a terminus ante quem this portion of the church was roofed, suggesting that works were at a final stage in 1705. Looking at the cathedral's building accounts we can, in fact, trace back a certain 'Geo. Reeves,' who, between October 1704 and May 1706, is employed by the master bricklayer Richard Billinghurst. Specifically, in October 1704, the bricklayers are 'Laying Bricks in Spandrils over ye Mid Isle Westward'; in November 1704, they are 'Laying bricks in the Vaulting over the Middle Isle W of the Dome'; and in May 1706, 'Cleansing the joynts of Brickwork in Dome and Mending the Paving in Church.' 
Moreover, at the same date, Richard Billinghurst gets paid 'For Bricklayers, \& Labourers to serve them, employed at the Dome from 16th April 1705 to 24th December following' (Wren Society 1938, XV, p. 135).

Figure 4: St Paul's Cathedral, loft space above nave, graffito.

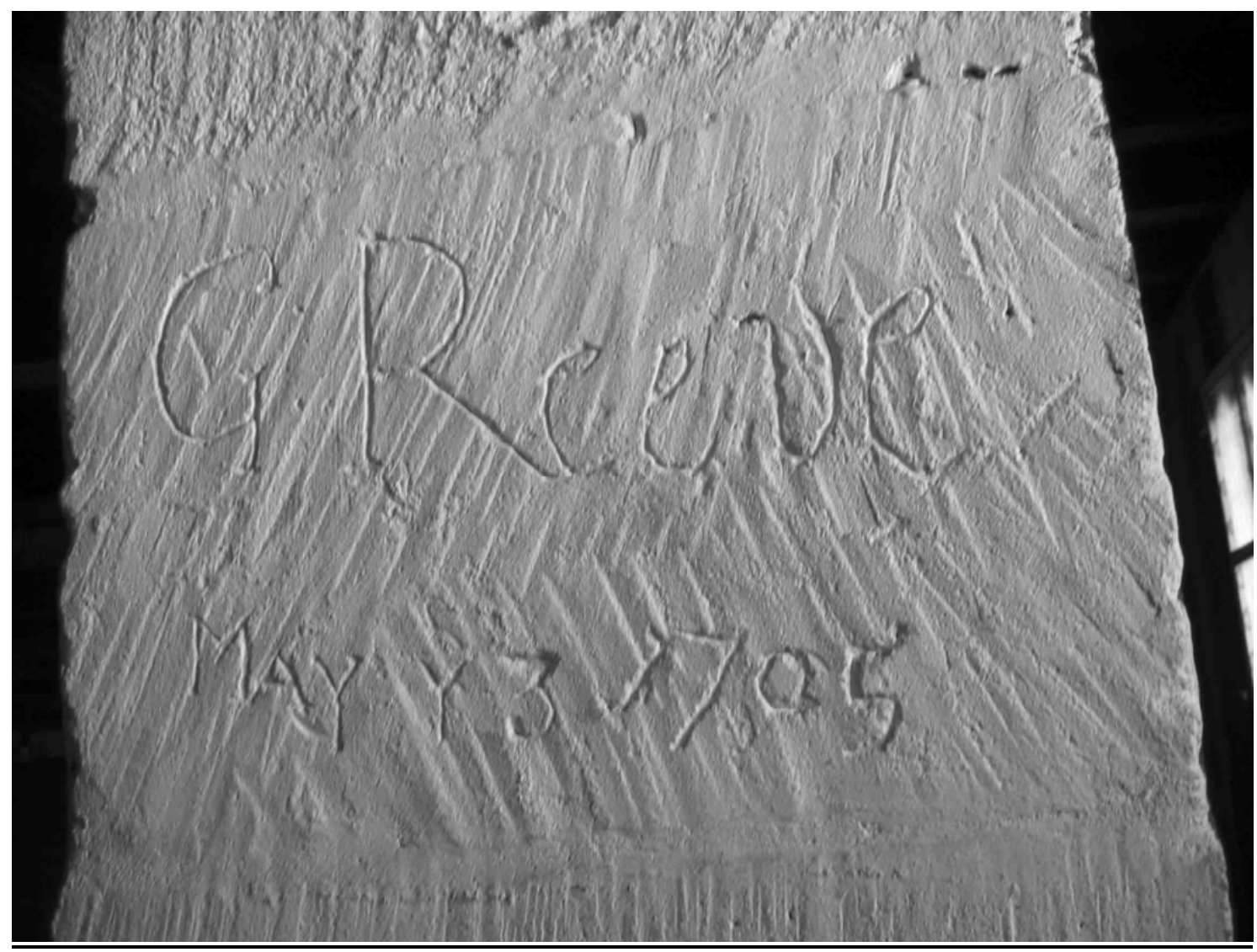

Photo by the author

5.2 Facts from Artefacts and Facts from the Page: Putting Evidence into Context

If we reach back to what Pucci calls the 'enciclopedia' and to our typological knowledge, we will discover that St. Paul's roof structures are far more significant than we have so far implied. In fact, they are a novelty in the context of seventeenth-century English building culture; before 
Wren, hammer-beam roof structures were the most common (Figure 5). ${ }^{33}$ Therefore, the presence of king post trusses and the use of metal elements to complement the timber structure in Wren's masterpiece are evidence of the introduction of new building techniques that arrived on the back of the new architectural style, which was derived from continental Renaissance architecture. ${ }^{34}$ In order to understand the path followed by this set of innovations, it is important to note that - as the sources make clear - they were introduced by the architects and not (as one might think) by the master carpenters (Campbell 1999, 2002).

Figure 5. Westminster Hall, hammer-beam roof structure (c.1399).

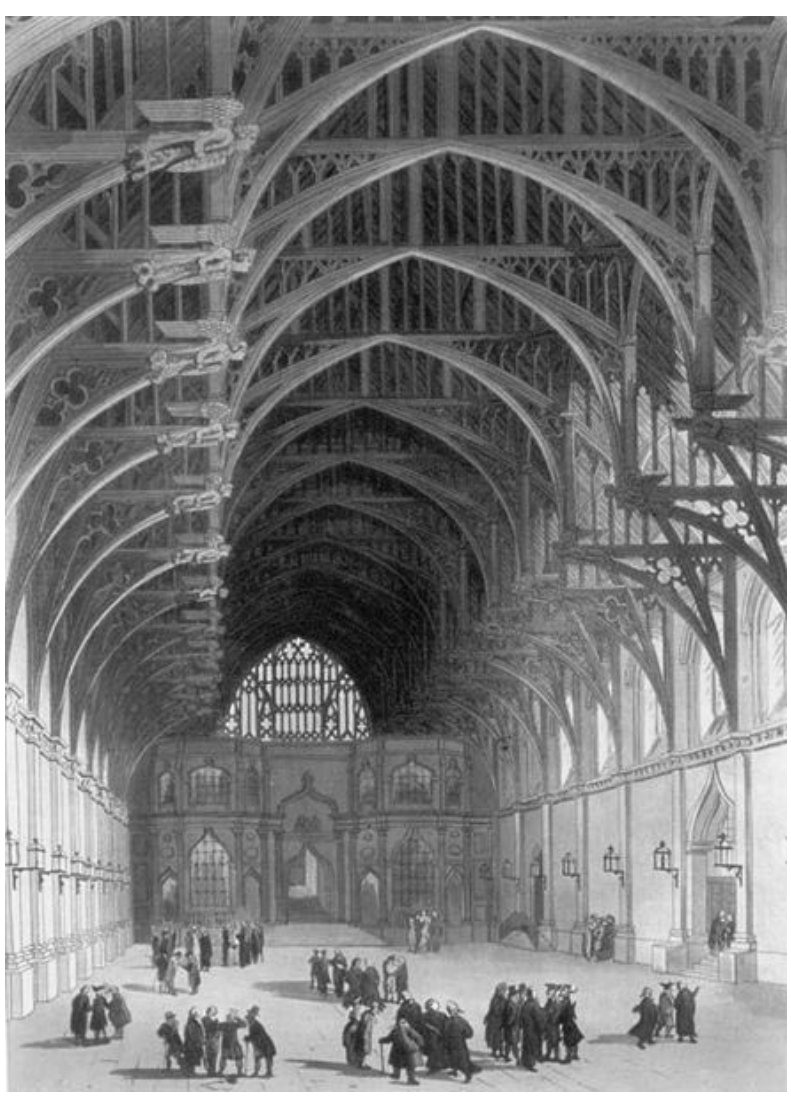

http://www.essential-architecture.com/LO/047-Westminster_Hall_edited.jpg

\footnotetext{
${ }^{33}$ King post trusses had already been occasionally used by Inigo Jones and, before him, Robert Smithson, but they were still unusual (Yeomans 1992, p. 26).

${ }^{34}$ The new style, as well as some innovations in the building techniques, had already been partially introduced by Inigo Jones, although the civil war kept him from building much (Yeomans 1992).
} 
Probable sources of inspiration for Wren's designs are to be seen in the Italian and French architecture of the time. In fact, some of the brilliant technical solutions Wren adopted, although new to the English architectural world, had been already widely discussed and established abroad. (Thinking of king post trusses, for instance, we look particularly at the Italian carpentry tradition.) But how did these facts about building techniques actually travel? Wren wasn't a travelled man - the only journey he made to the continent was a relatively brief one to France, where the kind of trusses used in St. Paul's were not particularly common. ${ }^{35}$ Therefore, we must assume that if the facts about carpentry techniques travelled to England through Wren, it was thanks to writings and drawings and descriptions, and not via his direct observation. We know for certain that Wren's library contained some important texts addressing these problems from a 'scientific' point of view. The most prominent one is Bernardino Baldi's "Exercitationes," which was also mediated through Wotton's "Elements." ${ }^{\text {"36 }}$ Baldi's work discusses in detail the shape and structural behaviour of a king post truss, but, being a book on mechanics, the sketches and descriptions presented are more explicative of general principles then useful for reproducing the structures in detail.

If we look for the sources that might have enabled Wren to import not just a general structural model, but also detailed technical solutions (which were obviously partially adapted to the local building tradition), we have to look further. King post trusses with struts - as those employed in St. Paul's - are a very old type of structure. Material evidence of their use goes back at least to the early Christian period, but they were probably already used well before that (Valeriani 2006a, p. 107-127, and 2008).

\footnotetext{
${ }^{35}$ It has been suggested that Wren might have also travelled to the Netherlands (Kuyper 1980).

${ }^{36}$ Baldi1621, see Italian translation and commentary in Becchi 2004. Wotton (1624).
} 
Nevertheless, there are various versions of king post trusses, differing from each other in how the elements are shaped, for example, or how they are connected to each other. The details of the structure adopted by Wren (which later became common in England) resemble very closely those shown in Serlio's treatise and its chapters on roofs (Figure 6). ${ }^{37}$ Evidence substantiating the thesis that Serlio was an important source for Wren's carpentry designs is given, amongst other things, by the king posts with joggled head described previously. ${ }^{38}$ This solution - not previously used in England - is unlikely to have been developed by a carpenter, being relatively impractical and difficult to make compared to other variants, as well as uneconomical. Therefore, it seems unreasonable to assume it was a 'faulty' interpretation by English carpenters of a generic instruction from the architect - rather, it can be advanced as evidence of what we could call 'faulty transmission' of facts on the part of the designer(s). Actually, this somewhat inconvenient solution is not found in any extant Italian roof, but is the result of a 'thought experiment' by Serlio (treatise writer and practicing architect, but not builder). Nevertheless, the technique was picked up by Wren (the scientist-architect, but not practical carpenter), who introduced it to

\footnotetext{
${ }^{37}$ Wren owned an edition of Serlio published in Venice in 1663 (probably Architettura di Sebastian Serlio bolognese, in sei libri diuisa, ... Nuouamente impressi in beneficio vniuersale in lingua latina, \& volgare, con alcune aggiunte. Sebastiani Serlij Bononiensis, De architectura libri sex. ..., In Venetia: per Combi, \& La Nou, 1663). As yet, it has not been possible to clarify if he knew the seventh book, where the most interesting notes and drawings as regard roof structures are found, although it is probable that he had seen it, as Jones, for example, owned a complete edition of Serlio's works (Tutte l'opere d'architettura, et prospetiua, di Sebastiano Serlio bolognese, ..., in Venetia: appresso Giacomo de' Franceschi, 1619).

${ }^{38}$ Another important point is made by the striking analogies between Wren's solution for the production of the long tie-beam at the Sheldonian Theatre and the technique clearly depicted in Serlio's seventh book. An in-depth analysis of Wren's carpentry for the Sheldonian, as well as of the links with French building practices of the time, would exceed the scope of this chapter. A first, provisional report on this subject is to be found in Valeriani 2006c, and an updated version is forthcoming.
} 
English carpentry. ${ }^{39}$ It then became a basic feature of the new structures, which came into English architecture on the back of the new architectural style. It is reasonable to assume that the differences in detail between the English and the Italian solutions are due to the inputs of the local carpenters, who recognised some weaknesses of the Serlian design and reinterpreted it.

\footnotetext{
${ }^{39}$ It must be noted that Inigo Jones had already designed posts with joggled heads (see, for example, Stoke Bruerne, Northamptonshire), but in contrast to Wren, also used some posts without enlarged heads, more in line with the Italian carpentry tradition (see, for example, Queen's Chapel, St James's Palace).
} 
Figure 6. Roof structures after Sebastiano Serlio

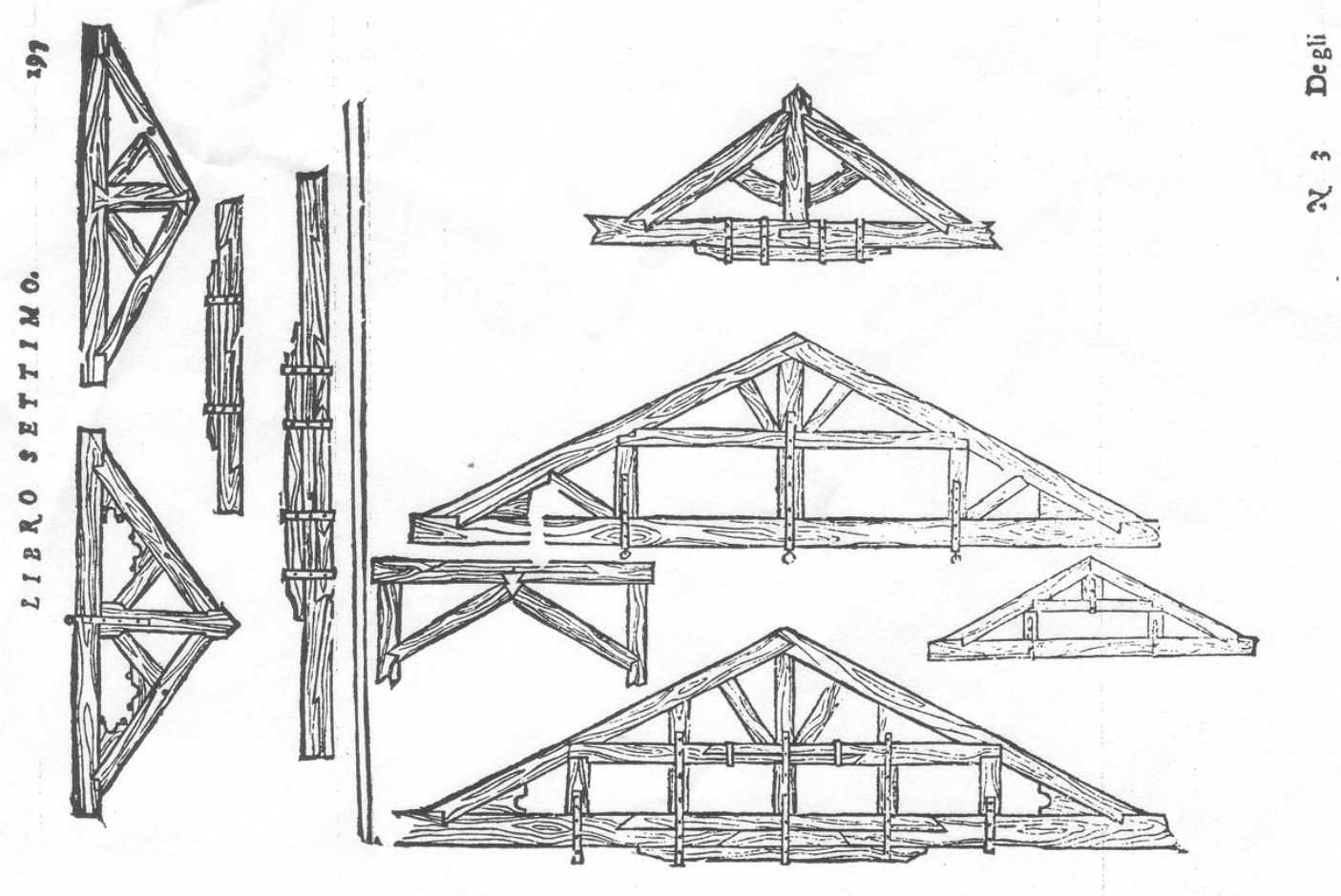

Serlio, 1575 , p. 197.

\section{$\underline{5.3 \text { Reprise }}$}

The material objects in the loft spaces of St. Paul's allowed us to retrieve - more or less directly - facts concerning the history of the building (such as construction date, structural problems arising after construction, etc.). But in other cases, the evidence 'stored' in the timber, plaster and iron could only act as interesting clues whose significance would only be understood via what we have been calling 'the encyclopaedia.' Comparison with typified data at the local level highlighted anomalies that called for historical explanations, but the use of a wider, international database has enabled us to recognise elements of continuity and to grasp broader historical phenomena, such as the introduction of new building techniques into England in the seventeenth century. Here, the material object gave us clues about an anomaly - the 
use of a new kind of structure - but the historian needed many more sources to understand why and how this specific carpentry technique came to be used. Once a possible source for these new technical facts had been identified (in Serlio's book), we looked at the material object again in detail to see if it fitted with the suggested source or not. Any 'discrepancies' led to further work to assess whether the presumed source was indeed the right one and, if so, how/why the original object/design/technical fact had changed while travelling.

In the case of St. Paul's, while discussing the most probable 'line' along which the new roof structures characterising English Renaissance architecture could have been imported on the back of the general architectural style, we have highlighted how the vehicles of travel in this case were books and drawings, rather than the architect's direct 'experience' of foreign structures. The contemporary thirst for renewal of the English architectural tradition ensured that such technical facts travelled well, remained quite intact and took root in good 'soil,' which allowed incoming techniques to succeed in replacing existing ones, albeit adapted at times to local traditions. While travelling, these facts were transformed along two main lines: Some changes were due to 'faulty interpretation' of original information, and others to the influence of the local craftsmen's existing know-how.

\section{6. "Everyday Things can Tell Secrets to Those Who Can Look and Listen" ${ }^{40}$}

As with all kinds of sources, the ability of facts to travel depends on an observer being able to 'read' the artefact and 'recognise' the facts. A lack of observer expertise can result in facts travelling badly - or even not

\footnotetext{
40 "Le cose di ogni giorno raccontano segreti, a chi le sa guardare ed ascoltare" Gianni Rodari, text of the song "Per fare un tavolo".'
} 
at all. This is not peculiar only to material objects: The same applies to any kind of information carried by whatever medium. For example, if you don't know they are written characters, you could easily misinterpret hieroglyphics as being purely decorative elements. And even if you know the signs are building words and phrases, you first need to figure out how to interpret them. Still - even if you don't recognise them as writing, or if you can't interpret them - the marks will stay on the object, together with the embedded facts they are carrying, waiting to be recognised or understood. This raises the issue of stability of facts' meanings - and material objects don't seem to differ significantly from other media in this regard: Despite the relative immutability of their materiality (in terms of, for example, chemical composition), the interpretation of facts that travel via artefacts still seems to change over time, and can depend greatly both on the observers' abilities, etc., and on the community/culture observing the object.

Taking for granted the importance of the social constructed identity of material objects and how the observation of those objects is socially determined, this chapter has aimed to analyse - with examples - how artefacts carry facts. Material objects have facts to tell or, as Lorraine Daston put it, 'Things talk and are not merely repeating or playing back the human voice' (Daston 2004, p. 11).

Looking at methodological differences between historical disciplines - archaeology and history - dealing with material objects in different ways, it has been argued that the material nature of the element storing or transporting facts influences how they travel and the methodologies needed to 'retrieve' them. Artefacts - material objects - carry a complex and layered collection of facts of different natures in a fundamentally different way from how facts are transported by the written page. This seems to be because material objects are a particular kind of vehicle that doesn't 'carry' facts as in an empty box - rather, the facts are embedded 
in their very materiality. Accent has been placed on the propensity of artefacts to carry facts about what happened, 'how' and 'when' rather than 'why.' (In like manner, written texts lend themselves to easily communicate intentions and reasons, but are not the best or most reliable vehicle to carry information about physical qualities and techniques.) Moreover, even though a text can inform about these aspects, it cannot normally offer the same richness of unintentionally expressed facts as can material objects. Although this is obviously a difference of degree rather than of kind, it still underlines a peculiarity in the ability of artefacts to carry facts, as against the written page or other 'vehicles.' 


\section{Bibliography}

Baldi, Bernardino. In mechanica Aristotelis problemata exercitationes, Moguntiae: Typis et Sumptibus Viduae Ioannis Albini, 1621.

Baird, Davis. Thing Knowledge: A Philosophy of Scientific Instruments, Berkeley, Calif.: University of California Press, 2004.

Becchi, Antonio. QXVI. Leonardo, Galileo e il caso Baldi: Magonza, 26 Marzo 1621, Venezia: Marsilio, 2004.

Brown, Bill. Things, Chicago, Ill., London: University of Chicago Press, 2004.

Buchli, Victor. Material Culture: Critical Concepts in the Social Sciences, London: Routledge, 2004.

Buchli, Victor. The Material Culture Reader, Oxford: Berg, 2002.

Burns, Arthur. "From 1830 to the Present," in St Paul's. The Cathedral Church of London 604-2004, edited by Derek Keene, Arthur Burns and Andrew Saint, London: Yale University Press, 2004, pp. 84112.

Campbell, James W. P. Sir Christopher Wren, the Royal Society, and the Development of Structural Carpentry 1660-1710, PhD Thesis, Department of Architecture, University of Cambridge, Trinity College, 1999.

Campbell, James W. P. "Wren and the Development of Structural Carpentry 1660-1710", ARQ: Architectural Research Quarterly, Volume 6, Issue 01. March 2002, p. 49-61.

Carandini, Andrea. Storie dalla terra, Torino: Einaudi, [1991] 2000.

Daston, Lorraine (editor). Things That Talk: Object Lessons from Art and Science, New York: Zone, 2004.

Eco, Umberto; Sebeok, Thomas A. The Sign of Three, Bloomington: Indiana University Press, 1983.

Friedrich, Karl. Die steinbearbeitung in ihrer entwicklung vom 11. bis zum 18. Jahrhundert, Augsburg 1932. 
Ginzburg, Carlo. "Spie. Radici di un paradigma scientifico", Rivista di storia contemporanea, vol. 1, 1978, pp. 1-14.

Ginzburg, Carlo. "Morelli, Freud, and Sherlock Holmes: Clues and Scientific Method," in Eco 1983, pp. 81-118.

Ginzburg, Carlo. Clues, Myth, and the Historical Method, Baltimore: Johns Hopkins University Press, 1989.

Ginzburg, Carlo. History, Rhetoric, and Proof, Hanover: University Press of New England, 1999.

Howlett, Peter and Morgan, Mary S. How Well Do Facts Travel?, Cambridge: Cambridge University Press, forthcoming.

Kuyper, Wouter. Dutch Classicist Architecture: A Survey of Dutch Architectrure, Gardens and Anglo-Dutch Architectural Relations from 1625-1700, Delft: Delft University Press, 1980.

Maier, Konrad, „Mittelalterliche Steinbearbeitung und Mauertechnik als Datierungsmittel," in Zeitschrift für Archäologie des Mittelalters, 3/1975, pp. 209-216.

Mannoni, Tiziano. "Ricerche sulle malte genovesi alla 'porcellana'," in Le scienze, le istituzioni, gli operatori alla soglia degli anni '90, Atti del IV convegno di scienza e beni culturali, Bressanone, 1988, pp. 137-142.

Mannoni Tiziano; Pesce, Giovanni and Vecchiattini, Rita. "Rapporti tra archeologia, archeometria e cultura materiale, nello studio dei materiali impiegati nelle opere portuali", in Anciennes Routes Maritimes Mêditerranéennes (ANSER): Le strutture dei porti e degli approdi antichi, edited by Anna Gallina Zevi, Rita Turchetti, Roma: Rubettino, 2004, pp. 113-126.

Miller, Daniel. Materiality, Durham: Duke University Press, 2005. Pesce, Giovanni and Ricci, Roberto. "The Use of Metakaolinite as Hydraulic Agent of Aerial Lime Plasters and Mortars. The Case 
Study of Genoa (Italy)," in Proceedings of the HMC08 Historical Mortars Conference, Lisbon September 2008.

Pucci, Giuseppe. "La prova in archeologia”, Quaderni storici, Volume 85, issue 1, 1994, p. 59-74.

Rogacki-Thiemann, Birte. Der Magdeburger Dom St. Mauritius et St.

Katharina - Beiträge zu seiner Baugeschichte 1207 bis 1567,

Petersberg: Michael Imhof Verlag, 2007.

Serlio, Sebastiano. Il settimo libro d'architettura di Sebastiano Serlio Bolognese, Frankfurt: Officina typografica Andreae Wecheli, 1575.

Tarule, Robert. The Artisan of Ipswich, Baltimore: John Hopkins University Press, 2004.

Tilley, Christopher Y. et al. Handbook of Material Culture, London: SAGE, 2006.

Valeriani, Simona. 'In the Ancient Forme.' The Reception and 'Invention' of Ancient Building Techniques in Early Modern Times, Hephaistos. New Approaches in Classical Archaeology and Related Fields, Volume 26, 2008, p.169-188.

Valeriani, Simona. Kirchendächer in Rom - Zimmermannskunst und Kirchenbau von der Spätantike bis zur Barockzeit. Capriate ecclesiae - Contributi di archeologia dell'architettura per lo studio delle chiese di Roma, Berliner Beiträge zur Bauforschung und Denkmalpflege III, Petersberg: Imhof Verlag, 2006a.

Valeriani, Simona. "I Metodi dell'archeologia dell'architettura applicati allo studio delle coperture lignee di alcune basiliche a Roma," in Archeologie. Studi in onore di Tiziano Mannoni, edited by Nicola Cucuzza and Maura Medri, Bari: Edipuglia, 2006b, pp. 519-522.

Valeriani, Simona. "The Roofs of Wren and Jones: A SeventeenthCentury Migration of Technical Knowledge from Italy to England," Working papers on The Nature of Evidence: How Well Do 'Facts' Travel?, 14/06, LSE, Department of Economic History 2006c 
(http://www.Ise.ac.uk/collections/economicHistory/pdf/FACTSPDF/1 406Valeriani.pdf)

Valeriani, Simona. "La Bauforschung a Lubecca: metodi di datazione", Archeologia dell'architettura, Vol. 4, 1999, pp. 83-92.

Vecchiattini, Rita. "Unità produttive perfettamente organizzate: le

calcinare di Sestri Ponente - Genova", Archeologia dell'Architettura, III, 1998, p. 141 - 152.

Wotton, Henry. The Elements of Architecture, London, 1624.

Wren Society. Photographic Supplement of St. Paul's Cathedral and Part III of the Building Accounts from October 1st, 1695 to June 24th, 1713. Also the Chapter House accounts, 1712-14 and Outline of Cathedral Accounts, 1714-25, vol. 15, Oxford: Oxford University Press, 1938.

Yeomans, David. The Architect and the Carpenter, London: RIBA Heinz Gallery, 1992. 


\section{LONDON SCHOOL OF ECONOMICS \\ DEPARTMENT OF ECONOMIC HISTORY}

WORKING PAPERS IN: THE NATURE OF EVIDENCE: HOW WELL DO "FACTS" TRAVEL?

For further copies of this, and to see other titles in the department's group of working paper series, visit our website at:

http://www.Ise.ac.uk/collections/economichistory/

2005

01/05: $\quad$ Transferring Technical Knowledge and innovating in Europe, c.1200-c.1800

Stephan R. Epstein

02/05: A Dreadful Heritage: Interpreting Epidemic Disease at Eyam, 1666-2000

Patrick Wallis

03/05: Experimental Farming and Ricardo's Political Arithmetic of Distribution Mary S. Morgan

04/05: Moral Facts and Scientific Fiction: $19^{\text {th }}$ Century Theological Reactions to Darwinism in Germany Bernhard Kleeberg

05/05: Interdisciplinarity "In the Making": Modelling Infectious Diseases Erika Mattila

06/05: $\quad$ Market Disciplines in Victorian Britain Paul Johnson

2006

07/06: Wormy Logic: Model Organisms as Case-based Reasoning Rachel A. Ankeny

08/06: How The Mind Worked: Some Obstacles And Developments In The Popularisation of Psychology Jon Adams 
09/06: $\quad$ Mapping Poverty in Agar Town: Economic Conditions Prior to the Development of St. Pancras Station in 1866 Steven P. Swenson

10/06: "A Thing Ridiculous"? Chemical Medicines and the Prolongation of Human Life in Seventeenth-Century England

David Boyd Haycock

11/06: Institutional Facts and Standardisation: The Case of Measurements in the London Coal Trade.

Aashish Velkar

12/06: Confronting the Stigma of Perfection: Genetic Demography, Diversity and the Quest for a Democratic Eugenics in the Post-war United States Edmund Ramsden

13/06: Measuring Instruments in Economics and the Velocity of Money

Mary S. Morgan

14/06: $\quad$ The Roofs of Wren and Jones: A Seventeenth-Century Migration of Technical Knowledge from Italy to England Simona Valeriani

15/06: Rodney Hilton, Marxism, and the Transition from Feudalism to Capitalism Stephan R. Epstein

2007

16/07: Battle in the Planning Office: Biased Experts versus Normative Statisticians Marcel Boumans

17/07: Trading Facts: Arrow's Fundamental Paradox and the Emergence of Global News Networks, 1750-1900 Gerben Bakker

18/07: Accurate Measurements and Design Standards: Consistency of Design and the Travel of 'Facts' Between Heterogenous Groups Aashish Velkar 
19/07: When Rabbits became Human (and Humans, Rabbits): Stability, Order, and History in the Study of Populations Paul Erickson and Gregg Mitman

20/07: $\quad$ Contesting Democracy: Science Popularisation and Public Choice Jon Adams

21/07 Carlyle and the French Enlightenment: Transitional Readings of Voltaire and Diderot T.J. Hochstrasser

22/02 Apprenticeship and Training in Premodern England Patrick Wallis

2008

23/08 Escaping the Laboratory: The Rodent Experimentsof John B. Calhoun and Their Cultural Influence Edmund Ramsden and Jon Adams

24/08 Travelling in the Social Science Community: Assessing the Impact of the Indian Green Revolution Across Disciplines Peter Howlett

25/08 Circulating Evidence Across Research Contexts: The Locality of Data and Claims in Model Organism Research Sabina Leonelli

26/08 The Lives of 'Facts': Understanding Disease Transmission Through the Case of Haemophilis Influenzae type $b$ Bacteria Erika Mattila

27/08 Regulating Data Travel in the Life Sciences: The Impact of Commodification Sabina Leonelli

28/08 A Journey Through Times and Cultures? Ancient Greek Forms in American Nineteenth Century Architecture: An Archaeological View Lambert Schneider

29/08 Behind the Facade: Elias Holl and the Italian Influence on Building Techniques in Augsberg Simona Valeriani 
30/08 What Happens to Facts After Their Construction?

Characteristics and Functional Roles of Facts in the Dissemination of Knowledge Across Modelling Communities

Erika Mansnerus (formerly Mattila)

31/08 'Voice' and the Facts and Observation of Experience Mary S. Morgan

32/08 Dilemmas in the Constitution of and Exportation of Ethological Facts

Richard Burkhardt

33/08 Travelling with the GDP Through Early Development Economic History Daniel Speich

34/08 'On A Mission' with Mutable Mobiles Mary S. Morgan

35/08 Agri-Technologies and Travelling Facts: Case Study of Extension Education in Tamil Nadu, India Peter Howlett and Aashish Velkar

2009

36/09 Indexing Nature: Carl Linnaeus (1707-1778) and his FactGathering Strategies

Staffan Muller-Wille and Sara Scharf

37/09 Acting with 'Facts' in Order to Re-model Vaccination Policies: The Case of MMR Vaccine in the UK, 1988 Erika Mansnerus

2010

38/10 Designed for Travel: Communicating Facts Through Images

Martina Merz

39/10 Facts and Building Artefacts: What Travels in Material Objects?

Simona Valeriani 